\title{
Model for Reconstruction of $\gamma$-Background during Liquid Atmospheric Precipitation
}

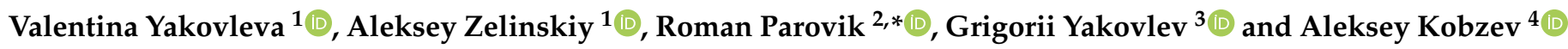 \\ 1 School of Nuclear Science \& Engineering, Nuclear Fuel Cycle Department, Tomsk Polytechnic University, \\ 634050 Tomsk, Russia; vsyakovleva@tpu.ru (V.Y.); azelinskiys@yandex.ru (A.Z.) \\ 2 Institute of Cosmophysical Research and Radio Wave Propagation, Far Eastern Branch of the Russian \\ Academy of Sciences, 684034 Kamchatskiy Kray, Russia \\ 3 Institute of Applied Mathematics and Computer Science, Tomsk State University, 634050 Tomsk, Russia; \\ yakovlev-grisha@mail.ru \\ 4 Institute of Monitoring of Climatic and Ecological Systems of Siberian Branch of the Russian Academy of \\ Sciences, 634055 Tomsk, Russia; kaa@imces.ru \\ * Correspondence: romanparovik@gmail.com
}

Citation: Yakovleva, V.; Zelinskiy, A.; Parovik, R.; Yakovlev, G.; Kobzev, A. Model for Reconstruction of $\gamma$-Background during Liquid Atmospheric Precipitation. Mathematics 2021, 9, 1636.

https://doi.org/10.3390/math9141636

Academic Editor: António M. Lopes

Received: 1 June 2021

Accepted: 9 July 2021

Published: 11 July 2021

Publisher's Note: MDPI stays neutral with regard to jurisdictional claims in published maps and institutional affiliations.

Copyright: (c) 2021 by the authors. Licensee MDPI, Basel, Switzerland. This article is an open access article distributed under the terms and conditions of the Creative Commons Attribution (CC BY) license (https:// creativecommons.org/licenses/by/ $4.0 /)$.

\begin{abstract}
With regard to reconstructing the gamma background dose rate, existing models are either empirical with limited applicability or have many unknown input parameters, which complicates their application in practice. Due to this, there is a need to search for a new approach and build a convenient, easily applicable and universal model. The paper proposes a mathematical model for reconstructing the temporal evolution of the ambient equivalent $\gamma$-radiation dose rate during rain episodes, depending on the density of radon flux from the soil surface, as well as the duration and intensity of rain. The efficiency of the model is confirmed by the high coefficient of determination $\left(R^{2}=0.81-0.99\right)$ between the measured and reconstructed ambient equivalent dose rate during periods of rain, the simulation of which was performed using Wolfram Mathematica. An algorithm was developed for restoring the dynamics of the ambient equivalent $\gamma$-radiation dose rate during rainfall. Based on the results obtained, assumptions were made where the washout of radionuclides originates. The influence of the radionuclides ratio on the increase in the total $\gamma$-radiation dose rate was investigated.
\end{abstract}

Keywords: radon decay products; simulation; model; gamma background; dose rate; atmospheric precipitation; rain shower

\section{Introduction}

Radon and its decay products are naturally occurring radionuclides found in the atmosphere around the globe. The isotope of radon ${ }^{222} \mathrm{Rn}$ is formed as a result of the radioactive decay of ${ }^{226} \mathrm{Ra}$ (radium) in the ${ }^{238} \mathrm{U}$ (uranium) chain contained in the Earth's crust. Being an inert gas with a half-life of 3.8 days, ${ }^{222} \mathrm{Rn}$ leaves the lithosphere and is easily dispersed in the atmosphere without interacting with its components. The $\gamma$-emitting radon decay products ${ }^{214} \mathrm{~Pb}$ (plumbum) and ${ }^{214} \mathrm{Bi}$ (bismuth) have a short half-life of 26.8 and $19.9 \mathrm{~min}$, respectively, and therefore can accumulate in the atmosphere in sufficiently high activities. They can join aerosols existing in the atmosphere. When liquid atmospheric precipitation falls, raindrops are deposited on the Earth's surface-both non-radioactive aerosols ${ }^{214} \mathrm{~Pb}$ and ${ }^{214} \mathrm{Bi}$.

The deposition of radionuclides causes an increase in gamma activity, and as a consequence, an increase in the ambient equivalent dose rate during and after precipitation. In the field of environmental radiation monitoring (environmental radiation monitoring network) [1,2], the problem of decomposition of the gamma background is still relevant. This requires tools to describe the growth of background gamma radiation caused by naturally occurring radionuclides and precipitation. In addition to the influence on the result 
of radiation monitoring, the effect of precipitated ${ }^{214} \mathrm{~Pb}$ and ${ }^{214} \mathrm{Bi}$ radionuclides becomes an obstacle in the control of tectonic activity due to the registration of gamma radiation from the descendants of ${ }^{222} \mathrm{Rn}$ emanating from the fracture of the Earth's crust [3-7]. For the quantitative elimination of interference caused by the rainwater precipitation of ${ }^{214} \mathrm{~Pb}$ and ${ }^{214} \mathrm{Bi}$ radionuclides in [8] authors have proposed a method based on the analysis of a meteorological dataset. The measured dose rate in [8] was corrected by subtracting the calculated value based on the regression coefficient between the amount of precipitation and the radiation dose. In [8], scientists used wavelet algorithms to suppress precipitation noise and achieved good results. For gamma spectrometry, using the law of simple radioactive decay, excellent results (determination coefficient $R^{2}=0.91$ ) were obtained for reconstructing the temporal evolution of the net counting rate of the ${ }^{214} \mathrm{~Pb}$ isotope (reproducible model for reconstructing the temporal evolution of the ${ }^{214} \mathrm{~Pb}$ ) [9].

Although the fundamental physics of the formation of clouds and precipitation has been known for a long time [10], a comprehensive quantitative model of this phenomenon has not yet been developed due to the insufficient accuracy of knowing the parameters of processes in clouds. At present, the dynamics of radioactive fallout is being actively monitored, including with the aim of verifying existing models and adjusting their parameters [9-19]. Observing the radon decay products dynamics is a useful tool in studying the chemistry and physics of atmospheric aerosols, cloud formation and atmospheric mass transfer. Research on natural atmospheric radiation is of great importance in applications such as human health and the radiation safety of nuclear power plants.

The aim of this work was to develop a model for the temporal reconstruction of the gamma background during the liquid atmospheric precipitation.

First, in this article, the procedure radiation monitoring is shown and the equipment used for measurements of liquid atmospheric precipitation is described. Second, the new mathematical model will be presented with accounting all measured quantities. Then, in the article, differential equations solutions and results of the simulations will be shown. Lastly, results regarding the reconstruction of the real $\gamma$-radiation dose rate for several cases of rain will be discussed in detail with the indication of our vision for the future development of this model.

\section{Mathematical Model}

Whilst the equations for the balance of activities in the air have been known for a long time [10], our new approach is that we directly model the dynamics of radionuclides in an air column that starts from the Earth's surface with an area of $1 \mathrm{~m}^{2}$ and extends to the lower edge of the clouds.

We do not model the vertical profile of volumetric activity in the atmosphere, but operate with integral activities in the air column.

Our approach greatly simplifies the modeling of the activity deposited on the ground by narrowing the set of input parameters to quantities that can be easily measured, such as radon flux density, precipitation intensity and the height of the cloud lower edge. Precipitation intensity is measured with OPTIOS optical precipitation gauge with a high resolution of $1 \mathrm{~s}$ [20] and DAVIS Rain collector II shuttle gauge. Data for the lower edge of the clouds are readily available on the Internet (https:/ / rp5.ru, accessed on 1 July 2021). The dose rate of gamma radiation was measured by using an scintillation gamma detector BDKG-03 (ATOMTEX, Minsk, Republic of Belarus). The radon flux density was measured using a RTM-2200 radiometer (SARAD GmbH, Dresden, Germany).

To simulate the dynamics of the $\gamma$-background during the periods of liquid atmospheric precipitation created by the isotopes ${ }^{214} \mathrm{~Pb}$ and ${ }^{214} \mathrm{Bi}$ deposited on the Earth's surface, it was assumed that radionuclides are washed out only from the subcloud space. This allows for an air column with a height $h$ (the height of the lower boundary of the cloud) and a base of $1 \mathrm{~m}^{2}$ to define the integral value $A_{i}^{h}(t)=\int_{0}^{h} A_{i}(z, t) d z$. Here, $A_{i}(z, t)$ is a distribution function (over height $z$ and time $t$ ) of the volumetric activity of the $i$-radionuclide, measured in $\mathrm{Bq} \cdot \mathrm{m}^{-3}$, where $i$ is ${ }^{222} \mathrm{Rn},{ }^{218} \mathrm{Po}$ (polonium), ${ }^{214} \mathrm{~Pb},{ }^{214} \mathrm{Bi}$. Let $A_{i}^{h 0}=A_{i}^{h}(t=0)$. 
Remark 1. Here, for the volumetric activity A of the isotopes ${ }^{222} \mathrm{Rn},{ }^{218} \mathrm{Po},{ }^{214} \mathrm{~Pb},{ }^{214} \mathrm{Bi}$ in order to shorten the notation, we omit the numerical indices characterizing the mass numbers.

Under the condition of radioactive equilibrium, in the absence of atmospheric precipitation, the initial activity of plumbum and bismuth isotopes $A_{P b}^{h 0}, A_{B i}^{h 0}$ in the air column of height $h$ can be determined from the value of radon flux density from the soil surface $q_{R n}\left(\mathrm{~Bq} \cdot \mathrm{m}^{-2} \cdot \mathrm{s}^{-1}\right)$ from a simple ratio $A_{R n}^{h 0}=A_{P o}^{h 0}=A_{P b}^{h 0}=A_{B i}^{h 0}=q_{R n} / \lambda_{R n}$, where $\lambda_{R n}$ is the radioactive decay constant of radon ${ }^{222} \mathrm{Rn}, \mathrm{s}^{-1}$.

During the period of precipitation, the integral values of the activity of radionuclides in a column of height $h$ can be determined by solving the system of equations:

$$
\left\{\begin{array}{l}
\frac{d A_{R n}^{h}(t)}{d t}=q_{R n}-\lambda_{R n} \cdot A_{R n}^{h}(t), \\
\frac{d A_{P o}^{h}(t)}{d t}=\lambda_{P o} \cdot A_{R n}^{h}(t)-\left(\lambda_{P o}+L(t)\right) \cdot A_{P o}^{h}(t), \\
\frac{d A_{P b}^{h}(t)}{d t}=\lambda_{P b} \cdot A_{P o}^{h}(t)-\left(\lambda_{P b}+L(t)\right) \cdot A_{P b}^{h}(t), \\
\frac{d A_{B i}^{h}(t)}{d t}=\lambda_{B i} \cdot A_{P b}^{h}(t)-\left(\lambda_{B i}+L(t)\right) \cdot A_{B i}^{h}(t),
\end{array}\right.
$$

where $\lambda_{P o}, \lambda_{P b}$ and $\lambda_{B i}$ are the constants of the radioactive decay of isotopes ${ }^{218} \mathrm{Po},{ }^{214} \mathrm{~Pb}$, ${ }^{214} \mathrm{Bi}$, measured in $\mathrm{s}^{-1} ; L(t)=I(t) \cdot k_{1} \cdot k_{2}$ is a function of the washout coefficient versus time, measured in $\mathrm{s}^{-1}$; where $I(t)$ is the precipitation intensity function versus time; $k_{1}=10^{-5}(\mathrm{~h} /(\mathrm{mm} \cdot \mathrm{s}))$ is the absolute washout ability; $k_{2}$ is relative washout ability coefficient.

Remark 2. In the system of Equation (1), to obtain the first line, it is necessary to use the law of simple radioactive decay: $\frac{d N(t)}{d t}=-\lambda N(t)$. In our case, this law describes the loss of radon atoms due to the process of their radioactive decay. Furthermore, since the activity is described by the expression $A(t)=\lambda N(t)$, then by multiplying the left and right sides of the decay law equation by $\lambda_{R n}$, we obtain $\frac{d A_{R n}^{h}(t)}{d t}=-\lambda_{R n} \cdot A_{R n}^{h}(t)$. Radon continuously exhales into the subcloud space from the soil. This exhalation must be taken into account by adding the radon flux density from the soil surface $q_{R n}$ to the right side of the equation.

For the second, third and fourth lines, the logic remains the same. The generation of radionuclides here occurs due to the decay of the parent element. For example, decayed radon turns into polonium and is taken into account by adding the coefficient $\lambda_{R n} \cdot N_{R n}^{h}(t)$ to the right side of Equation (here, $N_{R n}^{h}(t)$ is the number of atoms of the substance in the air column), which after multiplying the equation by $\lambda_{P_{0}}$ and the corresponding transformations takes the form $\lambda_{P_{0}} \cdot A_{R n}^{h}(t)$. The washout from the subcloud space is taken into account by the decrease in the activity of the corresponding radionuclides using the washout coefficient, for example, for polonium it is $L(t) \cdot A_{P o}^{h}(t)$.

The system of Equation (1) has the initial condition:

$$
A_{R n}^{h 0}=q_{R n} / \lambda_{R n} ;
$$

According to study [16], the radioactive equilibrium in the subcloud air could be shifted, therefore, we also simulated the dynamics of radon decay products activity in the subcloud atmosphere with the following ratios:

$$
A_{R n}^{h 0}: A_{P o}^{h 0}: A_{P b}^{h 0}: A_{B i}^{h 0}=1.00: 1.00: 0.60: 0.38 .
$$

Knowing the integral values of the radon decay products activities in the atmospheric column $A_{P 0^{\prime}}^{h}, A_{P b}^{h}$ and $A_{B i}^{h}$, one can proceed to the activities of $\mathrm{A}_{P_{0}}^{s}, \mathrm{~A}_{P b}^{s}$ and $\mathrm{A}_{B i}^{s}$ of polonium, plumbum and bismuth isotopes precipitated by rain on the Earth's surface, measured 
in $\mathrm{Bq} \cdot \mathrm{m}^{-2}$ (we assume that at the initial moment of liquid atmospheric precipitation, $\left.A_{P o}^{s 0}=\mathrm{A}_{P b}^{s 0}=\mathrm{A}_{B i}^{s 0}=0\right)$ :

$$
\left\{\begin{array}{l}
\frac{d A_{P o}^{s}(t)}{d t}=L(t) \cdot A_{P o}^{h}(t)-\lambda_{P o} \cdot A_{P o}^{s}(t), \\
\frac{d A_{P b}^{s}(t)}{d t}=L(t) \cdot A_{P b}^{h}(t)+\lambda_{P b} \cdot A_{P o}^{s}(t)-\lambda_{P b} \cdot A_{P b}^{s}(t), \\
\frac{d A_{B i}^{s}(t)}{d t}=L(t) \cdot A_{B i}^{h}(t)+\lambda_{B i} \cdot A_{P b}^{s}(t)-\lambda_{B i} \cdot A_{B i}^{s}(t) .
\end{array}\right.
$$

In system (4), to obtain equations, it is necessary to apply the logic according to which system (1) was composed. The difference is that system (4) describes an increase in activity on the soil surface, at the same time as system (1) describes a decrease from subcloud space.

Then, for system (4), the washout coefficient $L(t)$ on the right side will be used with the positive sign, since it reflects the increase in activity on the soil surface due to its exit from the air system.

The joint solution of the systems of Equations (1) and (4) with the initial conditions (2) and (3) is implemented in the Wolfram Mathematica environment using the built-in function DSolveValue and has the form:

$$
\begin{aligned}
& \left\{\begin{array}{l}
A_{R n}^{h}=K_{R n}^{h} \exp \left(-\tau \cdot \lambda_{R n}\right), \\
A_{P o}^{h}=K_{P o}^{h} \exp \left(-\tau \cdot\left(L_{i}+\lambda_{P o}\right)\right), \\
A_{P b}^{h}=K_{P b}^{h} \exp \left(-\tau \cdot\left(L_{i}+\lambda_{P b}\right)\right), \\
A_{B i}^{h}=K_{B i}^{h} \exp \left(-\tau \cdot\left(L_{i}+\lambda_{B i}\right)\right), \\
A_{P o}^{s}=K_{P o}^{s} \exp \left(-\tau \cdot \lambda_{P o}\right), \\
A_{P b}^{s}=K_{P b}^{s} \exp \left(-\tau \cdot \lambda_{P b}\right), \\
A_{B i}^{s}=K_{B i}^{s} \exp \left(-\tau \cdot \lambda_{B i}\right),
\end{array}\right. \\
& K_{R n}^{h}=\frac{\left(\exp \left(\tau \cdot \lambda_{R n}\right)-1\right) \cdot q_{R n}+A_{R n}^{h 0} \cdot \lambda_{R n}}{\lambda_{R n}}, \\
& K_{P o}^{h}=\frac{A_{P o}^{h 0} \cdot\left(L_{i}+\lambda_{P o}\right)+\lambda_{P o} \cdot A_{R n}^{h}\left(\exp \left(\tau \cdot\left(L_{i}+\lambda_{P o}\right)\right)-1\right)}{L_{i}+\lambda_{P o}}, \\
& K_{P b}^{h}=\frac{A_{P o}^{h}\left(\exp \left(\tau \cdot\left(L_{i}+\lambda_{P b}\right)\right)-1\right)}{L_{i}+\lambda_{P b}}, \\
& K_{B i}^{h}=\frac{A_{B i}^{h 0} \cdot\left(L_{i}+\lambda_{B i}\right)+\lambda_{B i} \cdot A_{P b}^{h}\left(\exp \left(\tau \cdot\left(L_{i}+\lambda_{B i}\right)\right)-1\right)}{L_{i}+\lambda_{B i}}, \\
& K_{P o}^{s}=\frac{L_{i} \cdot A_{P o}^{h}\left(\exp \left(\tau \cdot \lambda_{P o}\right)-1\right)+\lambda_{P o} \cdot A_{P_{0}}^{s 0}}{\lambda_{P_{0}}}, \\
& K_{P b}^{s}=\frac{L_{i} \cdot A_{P b}^{h}\left(\exp \left(\tau \cdot \lambda_{P b}\right)-1\right)+\lambda_{P b} \cdot A_{P b}^{s 0}+\lambda_{P b} \cdot A_{P o}^{s}\left(\exp \left(\tau \cdot \lambda_{P b}\right)-1\right)}{\lambda_{P b}}, \\
& K_{B i}^{s}=\frac{L_{i} \cdot A_{B i}^{h}\left(\exp \left(\tau \cdot \lambda_{B i}\right)-1\right)+\lambda_{B i} \cdot A_{B i}^{s 0}+\lambda_{B i} \cdot A_{P b}^{s}\left(\exp \left(\tau \cdot \lambda_{B i}\right)-1\right)}{\lambda_{B i}},
\end{aligned}
$$

where $i$ is the time in the total duration of ambient dose equivalent rate fluctuations caused by precipitation; $L_{i}$ is a discretely specified washout coefficient for each time interval equal to $\tau$ and is a piecewise specified function of $t ; A_{R n}^{h 0}, A_{P 0^{\prime}}^{h 0}, A_{P b^{\prime}}^{h 0}, A_{B i}^{h 0}$ is an integral activity of the corresponding radionuclide in air column, calculated for the previous iteration or the starting value until the moment of precipitation (before precipitation, one needs to use (2)); $A_{R n}^{h}(t), A_{P o}^{h}(t), A_{P b}^{h}(t), A_{B i}^{h}(t)$ is an integral activity function versus the time of the corresponding radionuclide in the air column; $A_{P o}^{s}(t), A_{P b}^{s}(t), A_{B i}^{s}(t)$ is an activity function versus time of the corresponding radionuclide that precipitated on the soil surface; 
$A_{P O^{\prime}}^{s 0} A_{P b}^{s 0}, A_{B i}^{s 0}$ is an activity of the corresponding radionuclide calculated for the previous iteration or the initial value before precipitation.

\section{Algorithm for Reconstructing the Time Evolution of the Ambient Dose}

The general view of this system is convenient for implementing the algorithm for reconstructing the time evolution of the ambient dose equivalent rate based on repeating the cycles of calculating the variables. For this work, the sampling step of the time interval $\tau=60 \mathrm{~s}$. Then, the total time period covered by the model will be $i \cdot \tau$, where $i$ is the number of time periods of the duration of precipitation, as well as the time periods required to restore the ambient dose equivalent rate to the background value.

The use of the system of Equation (5) makes it possible to implement an algorithm for restoring the dynamics of the ambient equivalent $\gamma$-radiation dose rate (measured in $\mathrm{Sv} \cdot \mathrm{s}^{-1}$ ) during rain shower, which consists of the steps described below.

The first step is the simulation of radon and its decay products integral activity dynamics in the air column by using the system of Equation (1).

The second step is the simulation of the activity dynamics of precipitated ${ }^{218} \mathrm{Po},{ }^{214} \mathrm{~Pb}$ and ${ }^{214} \mathrm{Bi}$ isotopes on the soil surface by using the system of Equation (4).

Furthermore, the third step is the time evolution reconstruction of the ambient equivalent $\gamma$-radiation dose rate by multiplying activity functions $A_{P b}^{s}(t), A_{B i}^{s}(t)$ with the specific gamma ray dose constant for the corresponding radionuclide and then summing them.

Figure 1 shows the activity dynamics of ${ }^{214} \mathrm{~Pb}$ and ${ }^{214} \mathrm{Bi}$ precipitated on the soil surface and the calculated total $\gamma$-radiation dose rate excluding $\gamma$-background value before precipitation.

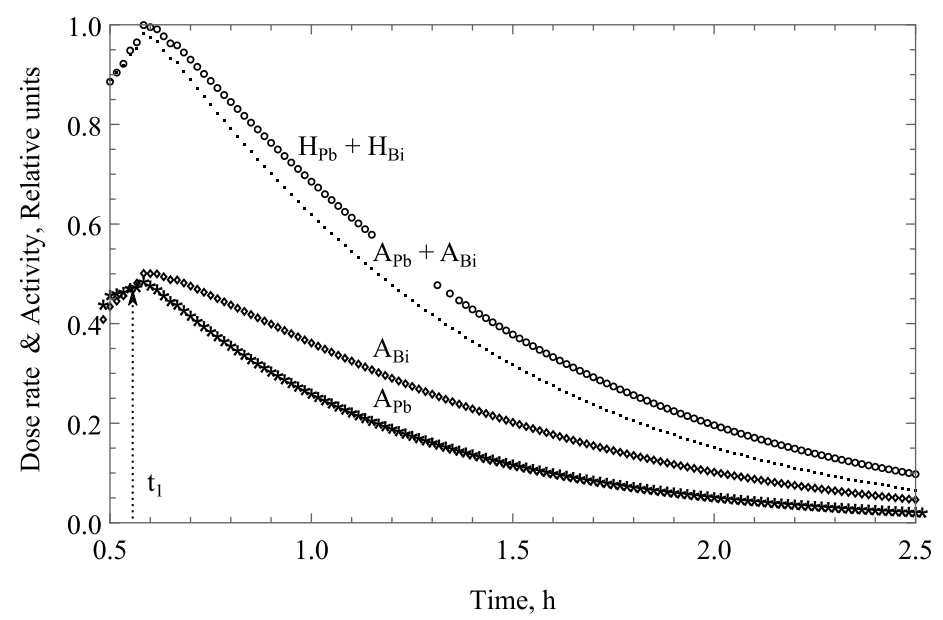

Figure 1. Dependence of the dose rate, activity of precipitated radionuclides on time. ${ }^{214} \mathrm{~Pb}$ activity on the soil surface (snowflakes). ${ }^{214} \mathrm{Bi}$ activity on the soil surface (diamonds). The total radionuclide activity on the soil surface (points). The total dose rate of $\gamma$-radiation due to the precipitated activity (circles).

As can be seen from Figure 1 over time, after the cessation of precipitation $t_{1}$, plumbum undergoes natural decay and passes into bismuth due to a shorter half-life. In the interval $>t_{1}$ the activity of bismuth increases over plumbum $A_{P b}^{s}<A_{B i}^{s}$. Due to the higher radiation characteristics of ${ }^{214} \mathrm{Bi}$, the dose rate decrease slower than the activity of other natural radionuclides in rainwater.

To switch to the registered equivalent dose rate $H(t)$, it is necessary to add the dose rate created by plumbum and bismuth $H_{P b}+H_{B i}$ and take into account the background component $H_{B k g}$, which is present before precipitation, that is, $H=H_{B k g}+H_{P b}+H_{B i}$ (Figure 2), where $H$ is the reading of the $\gamma$-radiation dosimeter; $H_{B k g}$ is a background value of the dose rate before the start of precipitation; $H_{P b}$ is the value of the dose rate formed by the $A_{P b}^{s}$ activity of plumbum; $H_{B i}$ is the value of the dose rate formed by the $A_{B i}^{s}$ activity of bismuth. 


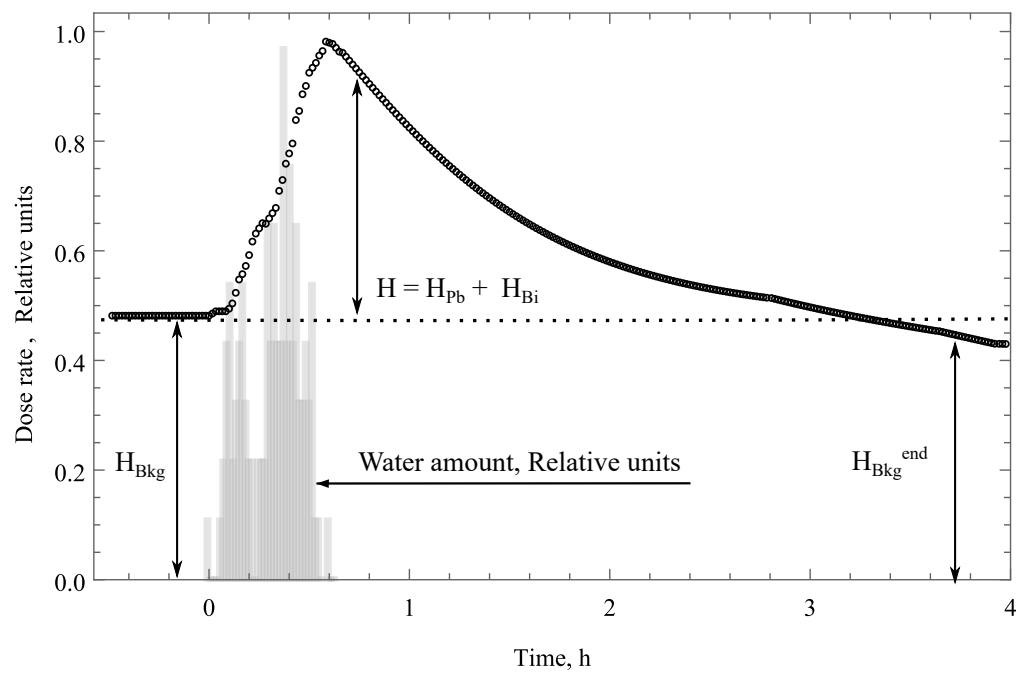

Figure 2. Dependence of the dose rate of $\gamma$-radiation on precipitation. Precipitation intensity (bar graph). Dose rate of $\gamma$-radiation (circles).

In Figure 2, the background value of the dose rate $H_{B k g}$ measured before the onset of precipitation is used to plot the readings of the $\gamma$-radiation dosimeter. $H_{P b}, H_{B i}$ are dose rates created by precipitated plumbum and bismuth activities $\left(A_{P b}^{s}, A_{B i}^{s}\right)$ calculated from the system of Equation (4). For the second and subsequent rainfall events, $H_{B k g}^{\text {end }}$ should be used instead of $H_{B k g}$.

Figure 3 shows a special case of rain with a duration of $t_{1}-t_{0}=40$ minutes. For such a case, the absence of bismuth in the subcloud space $\left(A_{B i 1}^{h 0}=0\right)$ during the period of precipitation leads to a decrease in total activity in rainwater at the end of the rain $t_{1}$ by about $20 \%$ compared to rain, in which the activities of bismuth and plumbum in the atmosphere are equal $\left(A_{B i 2}^{h 0}: A_{P b 2}^{h 0}=1: 1\right)$.

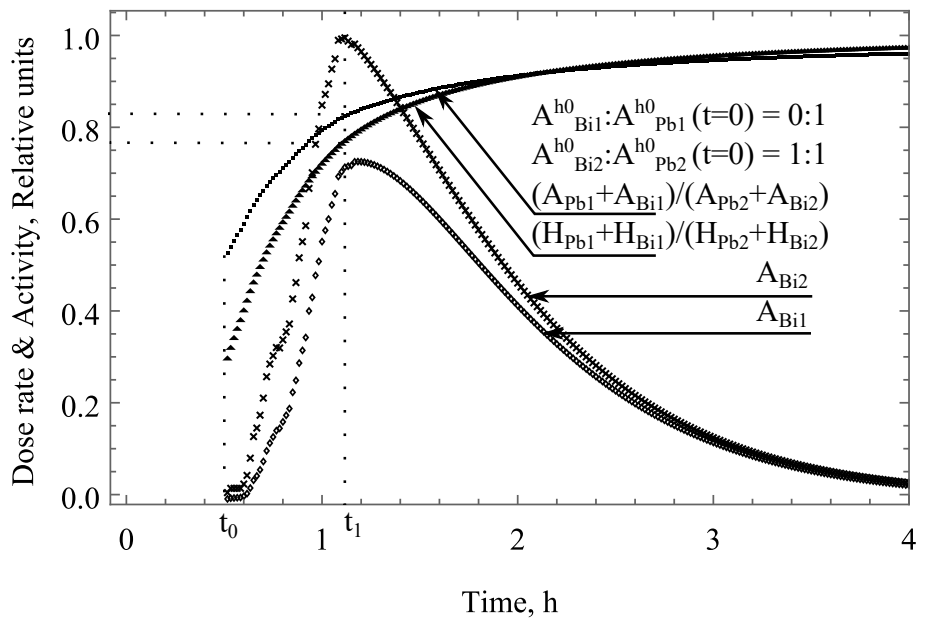

Figure 3. Dependence of the dose rate and activity of rainwater radionuclides on the activity of bismuth in the subcloud atmosphere. $A_{B i 1}$-rainwater bismuth activity in the absence of bismuth in the subcloud space (diamonds); $A_{B i 2}$ - the activity of bismuth in rainwater, and the activity of bismuth in the subcloud space is equal to the activity of plumbum (crosses). The ratio of the dose rates due to the activities of radionuclides in water, in the absence of and in the presence of the activity of bismuth in the atmosphere (triangles). The ratio of the total activities of water radionuclides, in the absence and in the presence of the activity of bismuth in the atmosphere (points).

Various cases of the ratios of plumbum and bismuth isotopes in the subcloud space were simulated, and from these results, it was concluded that if the ratio of radionuclides 
is unknown, then the error as a result of restoring the activity values can be up to $20 \%$ and the dose rate up to $25 \%$. Therefore, when modeling the dynamics of $\gamma$-background during periods of liquid atmospheric precipitation, it is extremely important to know the ratio of the main dose-forming $\gamma$-emitting radionuclides. The absence of bismuth in the subcloud space $A_{B i 1}^{h 0}=0$ does not lead to its complete elimination from rainwater due to the ongoing process of transition of decaying ${ }^{214} \mathrm{~Pb}$ to ${ }^{214} \mathrm{Bi}$.

\section{Results and Discussion}

To assess the effectiveness of the model, it is necessary to compare the data series obtained from the gamma radiation detector and the dose rate series reconstructed from the precipitation intensity. This means that to determine how much the restored function of the dose rate behavior corresponds to the real data, and therefore to calculate the coefficient of determination. This indicator is a statistical measure of goodness with which one can determine how well the regression equation matches the real data.

To test the described model, several cases of rain showers occurring in the city of Tomsk on the territory of the geophysical observatory of the IMCES SB RAS were used.

Figure 4 shows the following precipitation event that occurred on 7 August, 2017. For this event, according to meteorological data, the cloud base was at the height of $0.8 \mathrm{~km}$, the maximum precipitation intensity was $120 \mathrm{~mm} \cdot \mathrm{h}^{-1}$ and the total precipitation amount was $23 \mathrm{~mm}$. The measured value of the radon flux density before precipitation was, on average, $4.8 \cdot 10^{-4} \mathrm{~Bq} \cdot \mathrm{m}^{-2} \cdot \mathrm{s}^{-1}$. Calculations were made on the assumption of radioactive equilibrium between radon and its decay products in the atmosphere before the rain shower.

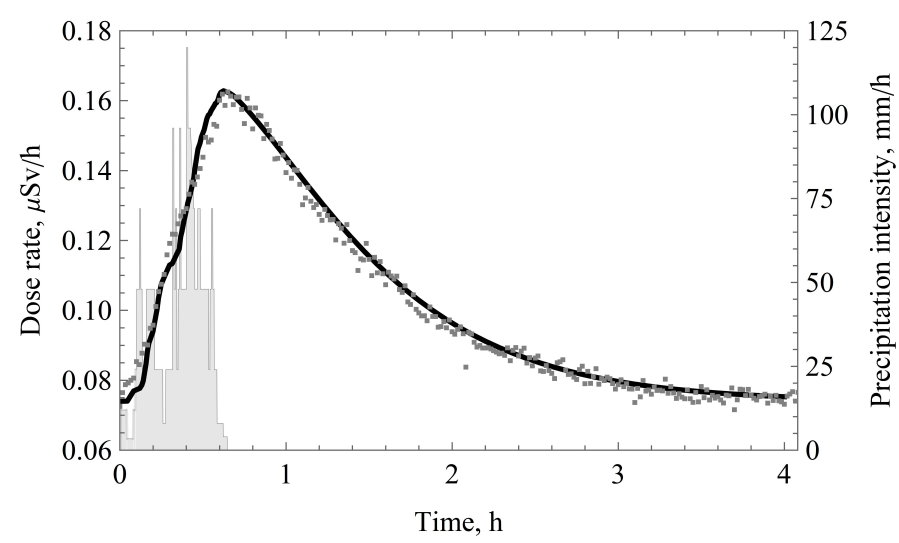

Figure 4. Influence of precipitation on the formation of the dose rate; measured dose rate (points); the dose rate reconstructed using the algorithm (solid line); and the precipitation intensity (filled bar graph).

For the rain shower shown in Figure 4, high agreement between the calculated and experimental data was obtained. The coefficient of determination $R^{2}=0.99$ and root mean square error $R M S E=0.004493\left[\mu \mathrm{Sv} \cdot \mathrm{h}^{-1}\right]$ for the ambient dose equivalent rate measured and recreated during a heavy rain.

Consider two consecutive heavy showers that occurred on 30 June 2017, with an interval of only about 30 min (Figure 5).

According to the meteorological data, for the first event, the maximum precipitation intensity was $168 \mathrm{~mm} \cdot \mathrm{h}^{-1}$, and for the second event this was $98 \mathrm{~mm} \cdot \mathrm{h}^{-1}$. The measured value of the radon flux density from the soil surface before precipitation was, on average, $4.5 \cdot 10^{-4} \mathrm{~Bq} \cdot \mathrm{m}^{-2} \cdot \mathrm{s}^{-1}$. The calculations were carried out on the assumption of radioactive equilibrium between radon and daughter products of its decay in the atmosphere before the beginning of showers.

The simulation results (Figure 5) showed that the developed mathematical model $\left(R^{2}=0.91\right)$ well describes the change in the dose rate of gamma radiation during two successive rain showers, the time interval between which is much shorter than the time of 
the dose rate decrease due to the decay of precipitated radon decay products to its initial background value of about $3 \mathrm{~h}$.

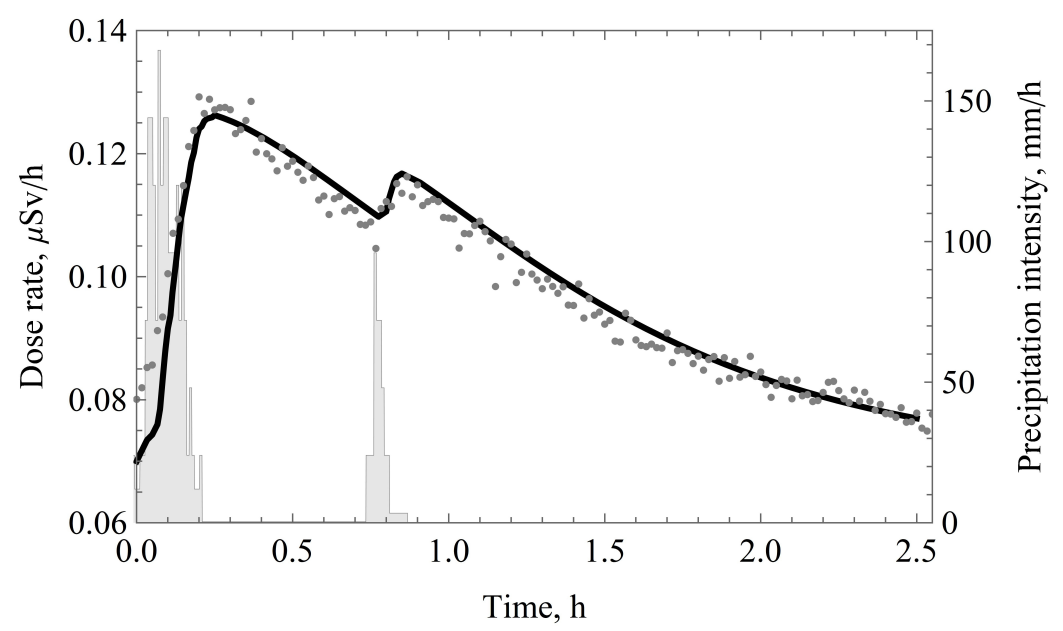

Figure 5. Influence of two consecutive rain showers on the formation of the dose rate; measured dose rate (points); the dose rate reconstructed using the algorithm (solid line; and the precipitation intensity (filled bar graph).

Figure 6 shows a case of precipitation that occurred on 30 July 2017. According to meteorological data, the height of the lower edge of the clouds was $1.2 \mathrm{~km}$, the intensity of precipitation at its maximum value was $55 \mathrm{~mm} \cdot \mathrm{h}^{-1}$, and the total amount of precipitation was $8.6 \mathrm{~mm}$. The measured value of the radon flux density before precipitation was, on average, $5.7 \cdot 10^{-4} \mathrm{~Bq} \cdot \mathrm{m}^{-2} \cdot \mathrm{s}^{-1}$.

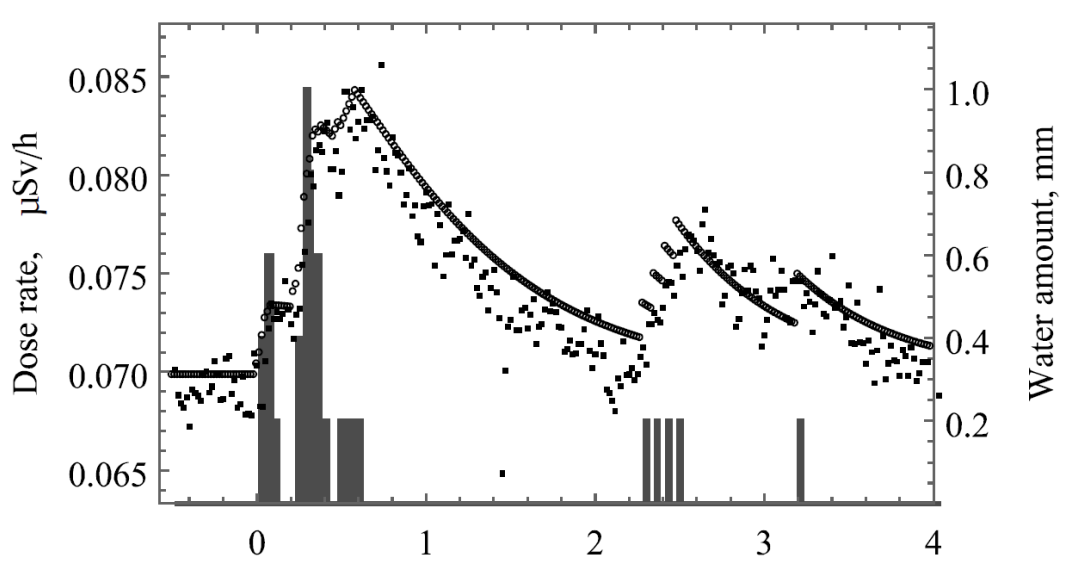

Time, $\mathrm{h}$

Figure 6. Influence of precipitation on the formation of the dose rate; measured dose rate (points); the dose rate reconstructed using the algorithm (circles); and the precipitation amount (bar graph)

For the reconstructed dynamics of the ambient equivalent $\gamma$-radiation dose rate, shown in Figure 6, the coefficient of determination $R^{2}=0.81$ indicates good agreement between the calculated and experimental data. In the interval of $1-2 \mathrm{~h}$ after the beginning of precipitation, an overestimated value of the reconstructed dose rate is observed in comparison with the registered one. This can be explained by soil moisture, and as a consequence, an increase in its attenuating ability in relation to $\gamma$-radiation. To simulate the $\gamma$-background during the second and third events of precipitation (Figure 6), the $H_{B k g}^{\text {end }}$ value of the previous precipitation was used.

\section{Conclusions}

Analysis of this work results allowed us to draw following important conclusions: 
1. A new mathematical model for the reconstruction of the dose rate during periods of liquid atmospheric precipitation was developed. The model was tested by comparing the experimental and reconstructed data. Its effectiveness is confirmed by a high coefficient of determination $\left(R^{2}=0.81-0.99\right)$ between the measured and recreated ambient dose equivalent rate during single and multiple rain events.

2. The new approach proposed by us has justified itself in the fact that for single high-intensity precipitations, our model with a small set of parameters that needs to be known describes the experimental data well enough.

3. As a consequence of the first conclusion, we can suppose that the radionuclides are washed out from the subcloud space but not from the cloud itself, which means that the contribution of radionuclides that are in the cloud is most likely minimal.

4. Algorithm for reconstructing the total dose rate proposed in this work is convenient for software implementation. It consists of three sequential steps: the simulation of radon decay products activity dynamics in the air column; on the soil surface; and time evolution reconstruction of the ambient equivalent $\gamma$-radiation dose rate.

In cases where we have a series of rain events with varying intensity, the model requires improvement as evidenced by the low coefficient of determination, and in this direction, we plan to further develop the model and also expand it to other types of precipitation, for example, drizzle.

Author Contributions: V.Y.- - research idea, formulation of research goals and objectives, guidance and consulting, analysis of calculation results. A.Z.- -analysis of literature, investigation, obtaining analytical solutions, analysis of experimental data, validation of model, part of the manuscript draft. R.P.-consulting, literature analysis, analysis of experimental data, part of the manuscript draft. G.Y.-investigation, obtaining analytical solutions, analysis of experimental data, visualization and verification of results, draft and final copy of the manuscript. A.K.- -analysis of literature, analysis of experimental data. All authors have read and agreed to the published version of the manuscript.

Funding: This research was supported by TPU development program and subject research IKIR FEB RAS "Physical processes in the system of near space and geospheres under solar and lithospheric influences" No AAAA-A21-121011290003-0.

Institutional Review Board Statement: Not applicable.

Informed Consent Statement: Not applicable.

Data Availability Statement: The data presented in this study are available on request from the corresponding author. The data are not publicly available due to privacy reasons.

Acknowledgments: The work was performed using equipment of TPU and IMCES SB RAS.

Conflicts of Interest: The authors declare no conflict of interest. The funders had no role in the design of the study; in the collection, analyses, or interpretation of data; in the writing of the manuscript, or in the decision to publish the results.

\author{
Abbreviations \\ The following abbreviations are used in this manuscript: \\ U uranium \\ $\mathrm{Ra} \quad$ radium \\ Rn radon \\ Po polonium \\ $\mathrm{Pb} \quad$ plumbum \\ Bi bismuth \\ TPU Tomsk Polytechnic University \\ IKIR FEB RAS Institute of Cosmophysical Research and Radio Wave Propagation, \\ Far Eastern Branch of the Russian Academy of Sciences \\ IMCES SB RAS Institute of Monitoring of Climatic and Ecological Systems \\ of Siberian Branch of the Russian Academy of Sciences
}




\section{References}

1. Avdic, S.; Demirovic, D.; Kunosic, S.; Pehlivanovic, B.; Kadic, I.; Ilic, Z. A study of daily variations of the outdoor background radiation measured in continuous mode in Federation of Bosnia and Herzegovina. J. Environ. Radioact. 2020, $217,106212$. [CrossRef] [PubMed]

2. Melintescu, A.; Chambers, S.D.; Crawford, J.; Williams, A.G.; Zorila, B.; Galeriu, D. Radon-222 related effects on ambient gamma dose. J. Environ. Radioact. 2018, 189, 67-78. [CrossRef] [PubMed]

3. Einarsson, P.; Theodórsson, P.; Hjartardóttir, Á.R.; Guðjónsson, G.I. Radon Changes Associated with the Earthquake Sequence in June 2000 in the South Iceland Seismic Zone. Pure Appl. geophys. 2008, 165, 63-74. [CrossRef]

4. Kumar, N.; Rawat, G.; Choubey, V.M.; Hazarika, D. Earthquake precursory research in western Himalaya based on the multiparametric geophysical observatory data. Acta Geophys. 2013, 61, 977-999. [CrossRef]

5. Wang, J.G.; Li, J.; Liu, Y.Y. An improved method for determining effective order rank of SVD denoising. J. Vib. Shock 2014, 33, 176-180.

6. Ye, Q.; Singh, R.P.; He, A.; Ji, S.; Liu, C. Characteristic behavior of water radon associated with Wenchuan and Lushan earthquakes along Longmenshan fault. Radiat. Meas. 2015, 76, 44-53. [CrossRef]

7. Guo, X.; Yan, J.; Wang, Q. Monitoring of gamma radiation in aseismic region and its response to seismic events. J. Environ. Radioact. 2020, 213, 106119. [CrossRef] [PubMed]

8. Li, C.Q.; Du, Y.G.; Li, B.G. A Wavelet Analysis on Annual Rainfall Variation in Hebei Province during 1965-2005. Prog. Geogr. 2010, 29, 1340-1344.

9. Bottardi, C.; Albéri, M.; Baldoncini, M.; Chiarelli, E.; Montuschi, M.; Serafini, A.; Strati, V.; Mantovani, F. Rain rate and radon daughters' activity. Atmos. Environ. 2020, 238, 117728. [CrossRef]

10. Takeuchi, N.; Katase, A. Rainout-washout model for variation of environmental gamma-ray intensity by precipitation. J. Nucl. Sci. Technol. 1982, 19, 393-409. [CrossRef]

11. Liu, H.; Daisuke, K.; Motokiyo, M.; Hirao, S.; Moriizumi, J.; Yamazawa, H. On the characteristics of the wet deposition process using radon as a tracer gas. Radiat. Prot. Dosim. 2014, 160, 83-86. [CrossRef] [PubMed]

12. Livesay, R.J.; Blessinger, C.S.; Guzzardo, T.F.; Hausladen, P.A. Rain-induced increase in background radiation detected by Radiation Portal Monitors. J. Environ. Radioact. 2014, 137, 137-141. [CrossRef] [PubMed]

13. Takeyasu, M.; Iida, T.; Tsujimoto, T.; Yamasaki, K.; Ogawa, Y. Concentrations and their ratio of 222Rn decay products in rainwater measured by gamma-ray spectrometry using a low-background Ge detector. J. Environ. Radioact. 2006, 88, 74-89. [CrossRef] [PubMed]

14. Yakovleva, V.S.; Nagorsky, P.M.; Cherepnev, M.S.; Kondratyeva, A.G.; Ryabkina, K.S. Effect of precipitation on the background levels of the atmospheric $\beta$-and $\gamma$-radiation. Appl. Radiat. Isot. 2016, 118, 190-195. [CrossRef] [PubMed]

15. Moriizumi, J.; Kondo, D.; Kojima, Y.; Liu, H.; Hirao, S.; Yamazawa, H. 214Bi/214Pb radioactivity ratio in rainwater for residence time estimation of cloud droplets and raindrops. Radiat. Prot. Dosim. 2015, 167, 55-58. [CrossRef] [PubMed]

16. Ambrosino, F.; Thinová, L.; Hýža, M.; Sabbarese, C. 214Bi /214Pb radioactivity ratio three-year monitoring in rainwater in Prague. Nukleonika 2020, 65, 115-119. [CrossRef]

17. Yakovleva, V.S.; Nagorskiy, P.M.; Cherepnev, M.S. Generation of ground atmosphere $\alpha$-, $\beta$-and $\gamma$-fields by natural atmospheric radionuclides. Vestnik KRAUNC. Fiz.-Mat. Nauk. 2014, 1, 86-96. [CrossRef]

18. Narayana Rao, T.; Uma, K.N.; Rao, D.N.; Fukao, S. Understanding the transportation process of tropospheric air entering the stratosphere from direct vertical air motion measurements over Gadanki and Kototabang. Geophys. Res. Lett. 2008, 35. [CrossRef]

19. Takeyasu, M.; Iida, T.; Tsujimoto, T.; Yamasaki, K. Measurements of concentrations and its ratio of radon decay products in rainwater by gamma-ray spectrometry with a low background germanium detector. Int. Congr. Ser. 2005, 1276, $289-290$. [CrossRef]

20. Kalchikhin, V.V.; Kobzev, A.A.; Korolkov, V.A.; Tikhomirov, A.A. Results of optical precipitation gauge field tests. Atmos. Ocean. Opt. 2018, 31, 545-547. [CrossRef] 